\title{
Haemophagocytic syndrome and COVID-19
}

\author{
Soledad Retamozo ${ }^{1}$ (D) P Pilar Brito-Zerón ${ }^{2,3} \cdot$ Antoni Sisó-Almirall $^{4,5}$ (D) $\cdot$ Alejandra Flores-Chávez $^{3}$. \\ María-José Soto-Cárdenas ${ }^{6} \cdot$ Manuel Ramos-Casals ${ }^{3,7,8,9}$
}

Received: 18 November 2020 / Revised: 19 December 2020 / Accepted: 22 December 2020 / Published online: 3 January 2021

(C) International League of Associations for Rheumatology (ILAR) 2021

\begin{abstract}
Primary and secondary haemophagocytic lymphohistiocytosis $(\mathrm{HLH})$ are hyperferritinaemic hyperinflammatory syndromes with a common terminal pathway triggered by different etiopathogenetic factors. HLH is characterised by a decreased capacity of interferon gamma production with an activated NK phenotype profile similar to other hyperinflammatory syndromes. Viruses are closely linked to the development of HLH as infectious triggers, and the break of tolerance to self-antigens is considered a critical mechanism involved in the development of immune-mediated conditions triggered by viral infections. Emerging studies in patients with COVID-19 are suggesting a key role of monocytes/macrophages in the pathogenesis of this viral infection, and there is a significant overlap between several features reported in severe COVID-19 and the features included in the HLH-2004 diagnostic criteria. Therefore, SARS-Cov-2, as other respiratory viruses, may also be considered a potential etiological trigger of HLH. The frequency of HLH in adult patients with severe COVID-19 is lower than 5\%, although this figure could be underestimated considering that most reported cases lacked information about some specific criteria (mainly the histopathological criteria and the measurement of NK cell function and SCD25 levels). Because HLH is a multi-organ syndrome, the diagnostic approach in a patient with severe COVID-19 in whom HLH is suspected must be carried out in a syndromic and holistic way, and not in the light of isolated clinical or laboratory features. In COVID-19 patients presenting with persistent high fever, progressive pancytopenia, and hepatosplenic involvement, together with the characteristic triad of laboratory abnormalities (hyperferritinaemia, hypertriglyceridaemia, and hypofibrinogenaemia), the suspicion of HLH is high, and the diagnostic workup must be completed with specific immunological and histopathological studies.
\end{abstract}

Keywords COVID-19 $\cdot$ Cytokine storm syndrome $\cdot$ Haemophagocytic syndrome $\cdot$ Hyperinflammatory syndrome $\cdot$ Macrophage activation syndrome $\cdot$ Multisystem inflammatory syndrome

\section{Introduction}

In January, 2020, a novel virus, severe acute respiratory syndrome coronavirus 2 (SARS-CoV-2), was identified as the

Manuel Ramos-Casals

mramos@clinic.cat

1 Instituto Modelo de Cardiología Privado S.R.L- Córdoba Argentina, Instituto Universitario de Ciencias Biomédicas de Córdoba (IUCBC), Córdoba, Argentina

2 Autoimmune Diseases Unit, Department of Medicine, Hospital CIMA- Sanitas, Barcelona, Spain

3 Laboratory of Autoimmune Diseases Josep Font, IDIBAPS-CELLEX, Barcelona, Spain

4 Grup Tranversal de Recerca en Atenció Primària, Institut d'Investigacions Biomèdiques August Pi i Sunyer (IDIBAPS), Barcelona, Spain causative agent for a cluster of pneumonia cases initially detected in Wuhan City (China). The lack of prior immunity to the virus has resulted in a rapid increase of infected patients across the globe [1], and the current status of this pandemic

5 Centre d'Atenció Primària Les Corts, Consorci d'Atenció Primària de Salut Barcelona Esquerre (CAPSBE), Barcelona, Spain

6 Department of Internal Medicine, Hospital Universitario Puerta del Mar, Cádiz, University of Cadiz, Cadiz, Spain

7 Department of Medicine, University of Barcelona, Barcelona, Spain

8 Department of Autoimmune Diseases, ICMiD, Hospital Clínic, Barcelona, Spain

9 Servei de Malalties Autoimmunes Sistèmiques, Hospital Clínic, C/ Villarroel, 170, 08036 Barcelona, Spain 
infection (December 15, 2020) includes more than 70 million confirmed worldwide cases and nearly two millions of deaths (https://covid19. who.int/?gclid=CjwKCAjwrcH3BRA p E i w A x j d P T c r u N m 9 O Z H Guw I c A z L 16 ZMuoB XCXswyh8SI2_DCQiVaAZ1 iNViNr GhoCBKsQAvD_BwE). The disease caused by SARS-CoV2 has a very wide clinical spectrum, the majority of patients (80\%) experienced mild disease, $14 \%$ severe disease and $5 \%$ a critical disease (respiratory and/or systemic failure). Inflammation has a predominant lung-centred pattern, although the loss of "front line" anti-viral defence mechanisms may activate in some patients an exaggerated hyperinflammatory response against the virus that actually contributes to worsening the infectious disease rather than accelerating its resolution [2].

Haemophagocytic lymphohistiocytosis (HLH) can be defined as a hyperferritinaemic hyperinflammatory syndrome that may be primary (a paediatric condition driven by germline mutations impairing granule-mediated cytotoxicity) or secondary (mainly reported in adults, and often driven by infection, malignancy systemic diseases or drugs [3]. Clinically, HLH is a systemic disease characterised by persistent fever, progressive cytopenias and multi-organ dysfunction caused by an uncontrolled immune activation associated with excessive cytokine production [3]. Immunopathologically, HLH is characterised by a decreased capacity of interferon gamma production and an activated NK phenotype profile (increased CD69, ICAM-1, HLADR, CCR5 expression) similar to other hyperinflammatory diseases [4]. CD163 macrophages are involved in hyperferritinaemic syndromes given their role in reticuloendothelial iron signalling, hence sHLH is also known as macrophage activation syndrome (MAS) especially in paediatric literature [5].

The frequent description of raised ferritin levels and its association with a worse prognosis stand out in early reported studies of COVID-19 [6], with a reasonable parallelism with HLH (hyperferritinaemic syndrome associated with high mortality), and therefore, several studies have suggested a close relationship between severe COVID-19 and HLH [7]. In this review, we analyse the different types of hyperinflammatory syndromes associated with COVID-19, their similarities and differences with respect to $\mathrm{HLH}$, and the degree of association between SARS-CoV-2 infection and HLH.

\section{Systemic inflammatory syndromes related to COVID-19}

The initial stage of direct damage caused by the SARS-CoV-2 in the respiratory tract can be followed by a subsequent hyperinflammatory response to the virus [8], with raised levels of inflammatory markers that have been correlated with poor outcomes (severe disease, mortality) [9]. However, the clinical phenotype of systemic inflammatory syndrome related to
COVID-19 is heterogeneous and appears to be mainly driven by the age, being close to Kawasaki disease in children, while in adults it shares significant features with cytokine release syndrome (CRS), acute respiratory distress syndrome (ARDS) or HLH.

\section{Multisystem inflammatory syndrome in children}

In April 2020, the Royal College of Paediatrics and Child Health in the UK described a paediatric syndrome that was called Paediatric Inflammatory Multisystem Syndrometemporally associated with SARS-CoV-2 (PIMS-TS) [10]; in the USA, this syndrome was referred as Multisystem Inflammatory Syndrome in children (MIS-C) [11], and an additional definition was further provided by the World Health Organization [12]. The three case definitions are similar and describe a population of children with evidence of a preceding SARS-CoV-2 infection (or exposure to a suspected or confirmed case) presenting with persistent fever, clinical features and laboratory abnormalities reflecting ongoing inflammation, and systemic involvement (including especially cardiac involvement) in the absence of other reasonable aetiologies [13]. In a recently reported consensus, patients with MIS-C have been classified into two main phenotypes (nonspecific phenotype, and Kawasaki disease-like phenotype) [14], although the distinction was mainly based on expert opinion rather than in a clearly-proven differentiated clinical and biological profile [15]. This syndrome has been reported exclusively in children and adolescents with COVID-19, but a recent study [16] have described 27 additional cases in adults (age $\geq 21$ years) that fulfilled MIS-C (Table 1). The authors have called the syndrome as MIS-A (Multisystem

Table 1 Definition of multisystem inflammatory syndrome in adults (MIS-A) [30]

Definition of multisystem inflammatory syndrome in adults (MIS-A)

1) A severe illness requiring hospitalisation in a person aged $\geq 21$ years.

2) A positive test result for current or previous SARS-CoV-2 infection (nucleic acid, antigen, or antibody) during admission or in the previous 12 weeks.

3) Severe dysfunction of one or more extrapulmonary organ systems (e.g. hypotension or shock, cardiac dysfunction, arterial or venous thrombosis or thromboembolism, or acute liver injury).

4) Laboratory evidence of severe inflammation (e.g. elevated CRP, ferritin, D-dimer, or interleukin-6).

5) Absence of severe respiratory illness (to exclude patients in which inflammation and organ dysfunction might be attributable simply to tissue hypoxia).

- Patients with mild respiratory symptoms who met these criteria were included.

- Patients were excluded if alternative diagnoses such as bacterial sepsis were identified. 
Inflammatory Syndrome in adults), all patients but one belonged to racial or ethnic minority groups. In $70 \%$ of reported cases, MIS-A was diagnosed 2-5 weeks after the development of the typical COVID-19 symptoms, while the remaining $30 \%$ did not present symptoms of acute infection (showing negative PCR) and SARS-CoV-2 infection was confirmed with SARS-CoV-2 antibody test results, suggesting that MIS$A$ and MIS-C could be immune-related postinfectious processes [16]. In both children and adults, MIS has a specific phenotype close to Kawasaki disease, with a very limited overlap with HLH.

\section{Hyperinflammatory syndromes in adults}

The clinical progression of COVID-19 towards a critical illness has been linked to the abnormal functioning of the two parts of the immune system (innate and adaptive responses). At early stages of the infection, a weak interferon response may delay the neutrophil recruitment to achieve an effective viral clearance, causing a sustained immune stimulation and the release of an exaggerated amount of proinflammatory cytokines and chemokines such as interleukin-6 (IL-6), CCL4 (macrophage inflammatory protein-1 $\beta$ ), CCL2 (monocyte chemoattractant protein 1) and CXCL9 (monokine induced by interferon- $\gamma$ ) [17]. Until now, little is known about what genetic and epigenetic factors can be related with the development of a hyperinflammatory syndrome triggered by SARS-CoV-2 infection [18], although it seems that IL-6 can play a central etiopathogenic role in severe COVID-19 infection. The IL-6-centred hypercytokinaemia has a close pathogenic link with hyperinflammatory and hypercoagulation responses, promoting the synthesis of several liver proteins, such as pentraxins (i.e. $\mathrm{C}$ reactive protein -CRP-) and ferritin, which are multifunctional proteins at the crossroads of immunity and inflammation, and it seems that the excess of circulating "free iron" detectable during severe inflammatory conditions can deteriorate the inflammatory reaction with the particular ability to induce a marked pro-coagulant state [19]. In patients with severe COVID-19 and increased serum levels of inflammatory mediators, the clinical scenario has been compared to that reported in other life-threatening conditions such as CRS, ARDS and HLH.

CRS is a condition associated with the release of large quantities of cytokines due to the dysregulated/perpetuated activation of lymphocytes and macrophages, leading to overwhelming systemic inflammation and multi-organ failure with high mortality [3] and that has been described in patients with graft-versus-host disease (GVHD) or in those receiving chimeric antigen receptor $\mathrm{T}$ cell therapies (CAR-T) [20]. Although the mechanisms of severe COVID-19 are still being elucidated [21], the term cytokine storm syndrome has become synonymous with its pathophysiology and even often switched with the term CRS [22]. However, a recent review has compared COVID-19 with other critical illnesses associated with elevated cytokine concentrations, showing that mean IL-6 concentrations were nearly 100 times higher in patients with CRS, 27 times higher in patients with sepsis and 12 times higher in patients with ARDS unrelated to COVID-19 in comparison with IL-6 concentrations reported in patients with COVID-19, questioning the use of the term cytokine storm in COVID-19 [23].

Viral pneumonias may be complicated by ARDS, a severe form of inflammatory pulmonary injury characterised by increased vascular permeability in the lungs, that is clinically defined by severe hypoxaemia and bilateral infiltrates on $\mathrm{X}$ Ray imaging after excluding other etiologies (mainly cardiac failure and volume overload). Some patients with COVID-19 infection may develop a severe, acute lung injury caused by the virus under the umbrella of the hyperinflammatory phenotype of ARDS [24, 25]. Other coronavirus such as severe acute respiratory syndrome $\mathrm{CoV}$ (SARS-CoV) and Middle East respiratory syndrome $\mathrm{CoV}$ (MERS-CoV) may also produce an acute lung injury associated with an exaggerated proinflammatory cytokine/chemokine systemic response [26]. In COVID-19 ARDS patients, a recent study has demonstrated a severely hyperinflammatory milieu in both the lungs and peripheral blood but characterised by activated lymphocytes in low numbers, a specific immunologic profile was identified in the lungs, consisting of a depleted and exhausted CD4 and CD8 T cell population prevailing those subtypes involved in both reparative and destructive processes [27].

Viruses are closely linked to the development of HLH in adults as infectious triggers. In a review of nearly 2200 reported cases of HLH reported in adults [28], infection was responsible of half the cases, with nearly $70 \%$ being linked to viruses, mainly herpesviruses. HLH was associated with viral pneumonias (adenovirus, influenza and parainfluenza viruses) in less than $5 \%$ of reported HLH-related infection cases [28]. Since 2000, we have identified 54 reported cases of HLH triggered by respiratory viruses (overwhelmingly related to adenovirus and influenza infections) (Supplementary Table 1); SARS-Cov-2, as other respiratory viruses, may also be considered a potential etiological trigger of HLH.

\section{Haemophagocytic syndrome related to COVID-19}

Macrophages are innate immune cells that respond to external threats by producing inflammatory molecules that eliminate microbes and promote tissue repair [29]. However, an exaggerated or dysregulated macrophage response can be damaging to the host, as is seen in the HLH induced by severe infections [30]. Several studies have suggested a pathogenic role of monocytes/macrophages in COVID-19 [31], although the specific drivers of activation of these cells and their 
specific contribution to the immunomediated damage remain inconclusive [29]. Exaggerated monocyte/macrophage activation can induce an overstated pro-inflammatory cytokine/ chemokine systemic response that may be included under the umbrella of hyperinflammatory syndromes that, like $\mathrm{HLH}$, have a similar etiopathogenic pathway (a specific external agent triggering a systemic immune dysregulation) [32], and a recent review has suggested that the hyperinflammatory syndrome associated with COVID-19 may have a significant pathogenic overlap with a viral-induced HLH (that is, macrophage activation with a cytokine overproduction and impairment of NK-cells and CD8+ T cells) [8].

In order to analyse the degree of association between SARS infection and HLH, we will first review the overlap of manifestations shared by severe COVID-19 and HLH, and then the available scientific evidence regarding the number of patients with severe COVID-19 who fulfil the criteria commonly used for the diagnosis of HLH in daily practice.

\section{Overlap between severe COVID-19 and HLH}

There is a significant overlap between several features reported in patients with severe COVID-19 and those included in the HLH-2004 diagnostic criteria (clinical features, laboratory abnormalities, immunological profile and histopathological data), which were developed designed for the HLH diagnosis for paediatric population but that are also used in adults.

Among those clinical features of HLH that can be overlapped with COVID-19, fever is a key marker of COVID-19, while splenomegaly is overwhelmingly not studied or not reported in the largest series of unselected patients with infection [33]. However, a review of recent studies centred on collect HLH-related features in COVID-19 patients has reported a frequency of hepatomegaly/splenomegaly in $15 \%$ of patients (Table 2) [33-42], suggesting that in COVID-19, splenomegaly is not much frequent as that reported in HLH patients.

With respect to haematological abnormalities, lymphopenia is a key feature of COVID-19 infection, not only by their high frequency (around half the cases) but also by their prognostic significance (it has been related to ARDS development, need of ICU care and poor survival), while thrombocytopenia and anaemia have been reported in $24 \%$ and $59 \%$, respectively [43]. Cytopenias are overwhelmingly asymptomatic, and symptomatic autoimmune cases (thrombocytopenic purpura, haemolytic anaemia) have been infrequently reported in COVID-19 infection. In contrast to HLH, the frequency of concomitant cytopenias (bicytopenia, pancytopenia) in patients with COVID-19 is very low (3-4\%) (Table 2).

Among biochemical parameters, the typical triad of abnormalities in HLH includes hypertriglyceridaemia, hypofibrinogenaemia and hyperferritinaemia. Triglyceride levels are not usually measured in the standard of care of patients with COVID-19, and in studies focused on investigating HLH-related features in COVID-19, 90/975 (9\%) patients showed hypertriglyceridaemia (Table 2) [33-35, 37, $38]$, and one study has reported no significant differences for mean TG levels between non-severe and severe COVID-19

Table 2 Frequency of the individual HLH-2004 classification criteria according to the data included in studies centred on collect HLH-related features in COVID-19 patients [34-43]

\begin{tabular}{|c|c|c|c|c|}
\hline HLH features & $N$ & $n$ & $\%$ & First author (reference) \\
\hline Hepatomegaly and/or splenomegaly & 152 & 23 & 15.1 & Hakim [34], Loscocco [35], Prieto-Pérez [36], Ruscitti [37], Wood [33] \\
\hline Cytopenias (2 lineages) & 990 & 32 & 3.2 & $\begin{array}{l}\text { Feld [38], Hakim [34], Loscocco [35], Prieto-Pérez [36], Ruscitti [37], } \\
\text { Wood [33] }\end{array}$ \\
\hline Cytopenias (3 lineages) & 152 & 6 & 3.9 & Hakim [34], Loscocco [35], Prieto-Pérez [36], Ruscitti [37], Wood [33] \\
\hline Ferritine $>500 \mathrm{ng} / \mathrm{mL}$ & 895 & 738 & 82.4 & Feld [38], Hakim [34], Prieto-Pérez [36], Wood [33] \\
\hline Ferritine $>1000 \mathrm{ng} / \mathrm{mL}$ & 855 & 513 & 60 & Feld [38], Hakim [34], Prieto-Pérez [36] \\
\hline Ferritine $>10,000 \mathrm{ng} / \mathrm{mL}$ & 895 & 57 & 6.3 & Feld [38], Hakim [34], Prieto-Pérez [36], Wood [33] \\
\hline Ferritine $<2000 \mathrm{ng} / \mathrm{mL}$ & 135 & 90 & 66.6 & Loscocco [35], Ruscitti [37], Wood [33] \\
\hline Ferritine $2000-6000 \mathrm{ng} / \mathrm{mL}$ & 135 & 33 & 24.4 & Loscocco [35], Ruscitti [37], Wood [33] \\
\hline Ferritine $>6000 \mathrm{ng} / \mathrm{mL}$ & 135 & 12 & 8.8 & Loscocco [35], Ruscitti [37], Wood [33] \\
\hline Hypertriglyceridaemia & 975 & 90 & 9.2 & Feld [38], Hakim [34], Loscocco [35], Ruscitti [37], Wood [33] \\
\hline Hypofibrinogenaemia & 1003 & 14 & 1.3 & $\begin{array}{l}\text { Feld [38], Hakim [33], Lee [39], Loscocco [35], Ruscitti [37], } \\
\text { Wood [33] }\end{array}$ \\
\hline Haemophagocytosis & 60 & 19 & 31.6 & Prieto-Pérez [36], Wood [33] \\
\hline HLH $>=5$ criteria & 22 & 0 & 0 & Feld [38] \\
\hline HScore $>169$ & 428 & 17 & 3.9 & $\begin{array}{l}\text { Clark [41], Giamarellos-Bourboulis [42], Hakim [3], Ruscitti [37], } \\
\text { Wood [33] }\end{array}$ \\
\hline
\end{tabular}


patients [44]. In addition, the use of tocilizumab should always be discarded as a potential cause of hypertriglyceridaemia in patients with COVID-19 [45, 46]. With respect to fibrinogen levels, patients with COVID-19 often have hyperfibrinogenaemia in opposite to $\mathrm{HLH}$, since systemic inflammation and increased IL-6 levels promote the synthesis of fibrinogen. However, some COVID-19 patients with a progressive severe disease may develop hypofibrinogenaemia preceding the development of severe disorders like disseminated intravascular coagulation (DIC) or HLH [47]. The frequency of hypofibrinogenaemia in COVID-19 reported in several studies is 1.3\% [33-35, 37-39], although in severe COVID-19 patients (admitted in the ICU, non-survivors), the frequency raised to $28-30 \%$ [ 48 , 49], and most patients with hypofibrinogenaemia fulfilled the International Society on Thrombosis and Haemostasis (ISTH) diagnostic criteria for DIC [48]. Finally, hyperferritinaemia is a frequent laboratory abnormality detected in COVID-19 patients, although most large series expressed the values as a mean, with only two reported categorised results with a frequency of raised ferritin levels in $45-78 \%$ of cases using different thresholds for defining hyperferritinaemia [33, 50, 51]. In studies centred on collecting HLH-related features in COVID-19 patients, hyperferritinaemia has reported in $82 \%$ of patients, with levels higher than $1000 \mathrm{ng} / \mathrm{mL}$ in $60 \%$ and higher than $10,000 \mathrm{ng} / \mathrm{mL}$ in only $6.3 \%$ of patients (Table 2 ). Since hyperferritinaemia is the hallmark of the "hyperferritinemic syndromes" [19], several authors have suggested that COVID-19 could be included into the umbrella of these syndromes that include systemic juvenile idiopathic arthritis, adult-onset Still's disease (AOSD), catastrophic antiphospholipid syndrome and HLH/MAS, all sharing a severe clinical presentation with a high mortality rate [52]. There is no specific threshold proposed for differentiating COVID-19 and HLH, although it seems that levels higher than $6000 \mathrm{ng} /$ $\mathrm{mL}$ (and especially, higher than $10,000 \mathrm{ng} / \mathrm{mL}$ ) are infrequently reported in patients with SARS-CoV-2 infection.

The HLH-2004 diagnostic criteria included two highly specific immunological criteria (decreased NK cell function and increased levels of IL-2R/CD25s). In viral infections, a defective cytotoxicity leads to the accumulation of antigenic stimuli, perpetuating inflammation and triggering tissue damage, and recent studies in COVID-19 patients have reported a decreased NK cell function, including a negative correlation between number of NK cells and IL-6 levels [53] and a profound depletion of NK cells [42], especially in severe patients [54]. IL-6 and IL-10 have the capacity to reduce NK cell cytotoxicity (IL-6 may reduce the expression of perforin and granzyme $\mathrm{B}$ while IL-10 negative correlate with NK cell cytotoxicity, through a reduction in IFN- and IL-2 expression) $[55,56]$. With respect to IL-2R levels, CD25 is expressed by T cells during immune activation and its soluble form (also known as IL-2R), is released into the bloodstream [57]. In COVID-19 patients, some studies have reported that sCD25 levels correlated positively with IL-6, IL-8, IL10 and TNF- $\alpha$, and negatively with lymphocyte count and disease severity [58], especially in patients with diabetes [59] or cancer [60]. Unfortunately, NK cell function and SCD25 levels have not been tested in the main series of COVID-19 patients with suspected HLH, although according to the results obtained in basic studies carried out in patients with COVID-19, it seems reasonable to suppose that we could find a similar immunological profile in patients with HLH associated with COVID-19 (reduced NK cell function and raised levels of CD25s).

Haemophagocytosis (phagocytosis of haematopoietic cells by activated macrophages) is considered the key marker of HLH but is not a sine qua non criterion for its diagnosis and should always be interpreted in the clinical context, since it is a physiological process that may be enhanced in some situations, including blood transfusions, infection, autoimmune diseases and other causes of bone marrow failure or red blood cell destruction. Haemophagocytic activity may not occur at any given time in any given organ during the disease course and may be absent in the initial stages of HLH, and therefore, repeat biopsies are recommended in patients with a high clinical and biological suspicion [28]. Although early studies stated that patients with severe COVID-19 may not be in a good enough condition to undertake a bone marrow examination searching for HLH, the severe clinical scenario is not different from that in HLH patients, and should be carried out when HLH is suspected. Haemophagocytosis can be linked to one of the key immunological abnormalities reported in severe COVID-19 (abnormal macrophage activation) and has been started to be described in patients with COVID-19, both in postmortem and clinical studies [33, 36, 61-63].

\section{HLH associated with COVID-19}

The number of reported cases of HLH in patients with COVID-19 has progressively increased throughout 2020. Table 3 summarises the main features of 60 patients with severe COVID-19 in whom HLH was suspected or diagnosed, and in whom details about the fulfilment of the individual HLH-2004 criteria are available [34, 36, 61, 64-83]. Most cases were men, with a mean age of 56 years, and the main presenting features included hyperferritinaemia (97\%), raised AST levels (93\%), fever (71\%), hypertriglyceridaemia (47\%), thrombocytopenia (48\%) and splenomegaly (44\%). Although most of these cases are reported by the authors as probable or definite HLH, only 8 (13\%) fulfilled at least 5 of the HLH-2004 diagnostic criteria. However, most patients have no data 
Table 3 A summary of the main features of 60 patients with severe COVID-19 in whom HLH was suspected and details about the fulfilment of the individual HLH classification criteria are available $[35,37,62,67-86]$

\begin{tabular}{|c|c|c|}
\hline & & $n / N(\%)$ \\
\hline Total cases & & $60(100)$ \\
\hline \multirow{13}{*}{ Country } & USA & $21(35)$ \\
\hline & Spain & $8(13.3)$ \\
\hline & Greece & $7(11.6)$ \\
\hline & UK & 7 (11.6) \\
\hline & France & $4(6.6)$ \\
\hline & Italy & $4(6.6)$ \\
\hline & Iran & $2(3.3)$ \\
\hline & Brazil & $2(3.3)$ \\
\hline & Belgium & $1(1.6)$ \\
\hline & Czech Republic & $1(1.6)$ \\
\hline & India & $1(1.6)$ \\
\hline & Netherlands & $1(1.6)$ \\
\hline & Switzerland & $1(1.6)$ \\
\hline Age & Mean age (range) & $55,6(7-91)$ \\
\hline Sex & Female & $19(31.7)$ \\
\hline Known immuno-suppression & & $14 / 42(33.3)$ \\
\hline \multirow[t]{4}{*}{ Fever $\left({ }^{\circ} \mathrm{C}\right)$} & Fever (yes) & $42 / 59(71.1)$ \\
\hline & 38-39 & $12 / 26(46.1)$ \\
\hline & $39-40$ & $6 / 26(23)$ \\
\hline & $>40$ & $8 / 26(30.7)$ \\
\hline \multirow[t]{3}{*}{ Megalies } & Hepatomegaly & $1 / 25(4)$ \\
\hline & Splenomegaly & $5 / 25(20)$ \\
\hline & Both & $6 / 25(24)$ \\
\hline \multirow[t]{4}{*}{ Cytopenias } & Nil lineage $(0)$ & $29 / 56(51.7)$ \\
\hline & One-cell lineage & $17 / 56(30.3)$ \\
\hline & Two-cell lineages & $6 / 56(10.7)$ \\
\hline & Three-cell lineages & $4 / 56(7.1)$ \\
\hline \multirow[t]{3}{*}{ Haemoglobin level } & $>12$ & $22 / 44(50)$ \\
\hline & $9-12$ & 8/44 (18.1) \\
\hline & $<9$ & $14 / 44(31.8)$ \\
\hline \multirow[t]{2}{*}{ Neutrophils count } & Normal & $32 / 35(91.4)$ \\
\hline & $\leq 1000$ & $3 / 35(8.6)$ \\
\hline \multirow[t]{2}{*}{ Platelets count } & Normal & $25 / 48(52.1)$ \\
\hline & $<100,000$ & $23 / 48(47.9)$ \\
\hline \multirow[t]{5}{*}{ Ferritin levels $(\mathrm{ng} / \mathrm{mL})$} & High & $56 / 58(96.6)$ \\
\hline & $<500$ & $5 / 56(8.9)$ \\
\hline & $500-1000$ & 9/56 (16.1) \\
\hline & $1000-10,000$ & $28 / 56(50.0)$ \\
\hline & $>10,000$ & $14 / 56(25.0)$ \\
\hline \multirow{2}{*}{ Hypertriglyceridaemia $(\geq 256 \mathrm{mg} / \mathrm{dL}, \geq 3 \mathrm{mmol} / \mathrm{L})$} & No & $19 / 36(52.7)$ \\
\hline & Yes & $17 / 36(47.2)$ \\
\hline \multirow[t]{2}{*}{ Hypofibrinogenaemia $(\leq 1.5 \mathrm{mg} / \mathrm{L}, \leq 150 \mathrm{mg} / \mathrm{dL}))$} & No & $24 / 33(72.7)$ \\
\hline & Yes & 9/33 (27.2) \\
\hline \multirow[t]{2}{*}{ AST (IU/l) } & $<30$ & $3 / 42(7.1)$ \\
\hline & $>30$ & $39 / 42(92.8)$ \\
\hline \multirow[t]{2}{*}{ Low sIL-2R levels and/or reduced NK cell function } & Present & $0 / 0(0)$ \\
\hline & Absence & $6 / 6(100)$ \\
\hline \multirow[t]{2}{*}{ Haemophagocytosis Bx } & Present & $15 / 18(83.3)$ \\
\hline & Absence & 3/18 (16.6) \\
\hline \multirow[t]{4}{*}{ HLH 2004 (number of criteria fulfilled)* } & 0 & $1(1.7)$ \\
\hline & $1-2$ & $30(50)$ \\
\hline & $3-4$ & $21(35)$ \\
\hline & $\geq 5$ & $8(13.3)$ \\
\hline \multirow[t]{3}{*}{ HScore* } & $\overline{<90}$ & 31 (51.6) \\
\hline & $100-160$ & 22 (36.6) \\
\hline & $\geq 169$ & 7 (11.6) \\
\hline \multirow[t]{2}{*}{ Outcome } & $\overline{\mathrm{ICU}}$ discharge & $24 / 60(40)$ \\
\hline & Death & $28 / 60(46.6)$ \\
\hline
\end{tabular}

*Most patients have no data on several HLH criteria (especially biopsy carried out in only $30 \%$ of patients, and measurement of NK function and SCD35 levels, measured in only 5\%) on several HLH criteria, especially biopsy that was carried out in only $30 \%$ of patients, and measurement of NK function and sCD35 levels, that were measured in only $5 \%$ of cases. Among the reported 60 cases, 8 were 
ongoing on the ICU, 24 were discharged and 28 died (a mortality rate of $54 \%$ ).

\section{Discussion}

The possible association between COVID-19 and HLH has generated an intense scientific debate with highly polarised positions. While some authors have suggested a close association and have recommended that all patients with severe COVID-19 should be screened for HLH [84], others argue that most of these patients actually develop an ARDS, sharing some HLH features, rather than presenting a systemic macrophage activation, the hallmark of HLH [85]. Probably, the clinical and biological scenario of severe COVID-19 is highly heterogeneous, mixing features of other life-threatening conditions like ARDS and HLH, and in fact, some authors are proposing a specific terminology and classification for severe COVID-19, such as that recently proposed by Webb et al. [86] (hyperinflammatory syndrome) including a specific set of criteria that could help to identify patients at higher risk of progression to mechanical ventilation and death (Table 4).

One of the key points for evaluating how close may be the association between HLH and severe COVID-19 is to analyse how many patients with severe COVID-19 fulfil the currently accepted HLH diagnostic criteria. According our review, it is clear that not all patients with severe COVID-19 will develop a fully blown HLH [87]. Less than 5\% of adult patients with severe systemic COVID-19 fulfil the HLH criteria, a rate that could be underestimated considering that most reported cases lacked information about several criteria (mainly the histopathological criteria and the measurement of NK cell function and sCD25 levels) and therefore, it is not possible to discard the development of a full HLH in these cases incompletely evaluated. In the view of the limitations for applying the standard HLH criteria, most studies have used the HScore, a classification score developed specifically for secondary, and especially malignancy associated, HLH in adults, that does not include any cytokine-related criteria [3]; a HScore > 169 has a sensitivity of $93 \%$ and a specificity of $86 \%$ for a HLH diagnosis. In studies searching for HLH in severe COVID-19 patients, there were 17 (4\%) out of 428 patients that had a score $>169[33,34,37,41,42]$ (Table 2), while in the individual reported cases summarised in Table 3, 7 (12\%) had a score equal or higher than 169. The use of HScore for COVID-19 patients has been questioned after highlighting some limitations regarding temperature, leukopenia (the score does not distinguish between neutropenia and lymphocytopenia), and the lack of published data on hypertriglyceridaemia, splenomegaly, hepatomegaly and BM haemophagocytosis, and therefore, some authors recommend against their use due to a potential lack of sensitivity [35]. In children, the frequency of MAS has been evaluated in those with a severe presentation
Table 4 Criteria proposed for hyperinflammatory syndrome associated with COVID-19 [23]

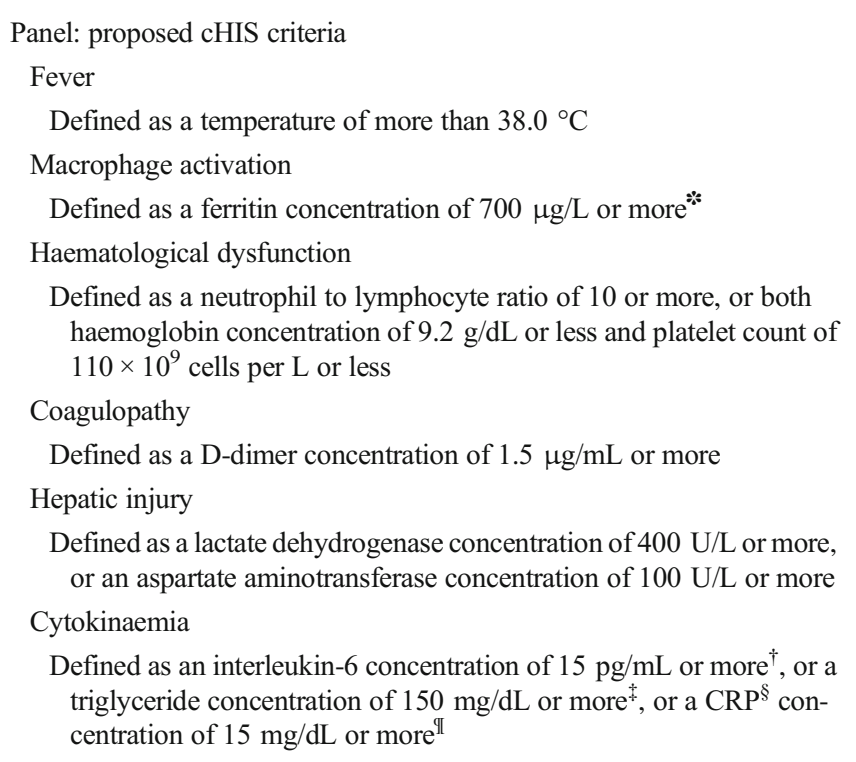

cHIS, COVID-19-associated hyperinflammatory syndrome; CRP, Creactive protein

* Ferritin concentration might be elevated in end-stage renal disease on haemodialysis

${ }^{\dagger}$ Original validation used a $10 \mathrm{pg} / \mathrm{mL}$ threshold; post-hoc analysis suggested that $15 \mathrm{pg} / \mathrm{mL}$ has better discrimination for poor outcomes

* Triglycerides might be elevated due to concomitant propofol administration

${ }^{\S}$ Not high-sensitivity CRP

${ }^{\mathrm{I}} \mathrm{CRP}$ was not included in the original validation; post-hoc analysis confirmed use as a third surrogate for cytokinaemia

(MIS-C) and is higher than the figure estimated in adults, with $30(25 \%)$ out of 118 children included in two studies $[88,89]$.

Despite the very rare occurrence of HLH in patients with SARS-CoV-2 infection (even in the most severe patients), some recommendations can be proposed in order to facilitate an early diagnosis of HLH in patients with severe COVID-19. An initial presentation consisting of a subacute persistence of high fever, together with enlargement of the liver and spleen, and a progressive severe pancytopenia (including especially thrombocytopenia), should be considered a highly suspicion clinical profile for HLH, always after discarding other etiologies (superimposed infections, cancer). The suspicion will be higher if the patient presents the typical HLH-related triad of laboratory abnormalities (hypertriglyceridaemia, low fibrinogen levels and hyperferritinaemia, especially very high levels, i.e. $>5000 \mathrm{ng} / \mathrm{mL}$ ). In these patients, a complete study (immunological markers, histopathological confirmation of haemophagocytosis) searching for HLH should be advised.

Once the diagnosis of HLH is confirmed in a patient with COVID-19, a differentiated therapeutic approach with respect to patients without HLH may be considered, since an early 
intervention could be essential to avoiding irreversible organspecific damages caused by HLH [90]. Unfortunately, many patients with severe COVID-19 will become critically ill before high-quality evidence of treatment efficacy is available and in daily practice, most physicians are extrapolating therapeutic data from current clinical experience in similar lifethreatening conditions (ARDS, sepsis, CRS and HLH). HLH requires a triple therapeutic approach including vital support measures, elimination of potential triggers (mainly infection) and suppression of the exaggerated inflammatory response, an approach that can be applied in patients with severe COVID19. Glucocorticoids are the key first-line option in patients with HLH [28] and also in those with COVID-19, considering the results of the RECOVERY trial [91], and their effect does not seem to hamper antiviral responses in patients with HLH associated with other viral infections [92]. Biological agents have also been considered for treating HLH. Among anticytokine agents, tocilizumab (anti-IL-6 receptor) has been reported effective in CRS associated with CAR-T therapy, an approach that is being considered for treating severe COVID19 patients [93]. The use of JAK inhibitors (baricitinib, tofacitinib) is currently under investigation in severe COVID-19 [94] with positive results recently reported in a controlled trial in association with remdesivir [95], as well as agents blocking GM-CSF (mavrililumab, lenzilumab) [96, 97]. Finally, emapalumab is a fully human anti-IFN gamma monoclonal antibody that has been approved in the US as second-line treatment of primary HLH [98] and that could be evaluated in adults with HLH-like presentations of COVID-19. Drugs modulating the immune response may be critical for treating HLH associated with severe COVID-19 [8], although neither the optimal timing nor the sequential schedule of using such therapies remains to be defined. Multidisciplinary management of severe COVID-19, with or without associated HLH, is essential.

\section{Conclusions}

The development of a life-threatening disease in patients with COVID-19 has brought most hospitals around the world to reach a level of usage of hospital beds (including conventional and intensive care beds) never seen in the modern history of medicine. Although it is a clinical scenario that affect less than $5 \%$ of people infected by SARS-CoV-2, this small percentage is critical considering we are dealing with a pandemic that has affected more than 70 million people worldwide in less than a year. The etiopathogenic mechanisms that drive such severe presentation in a such limited percentage of infected people are not fully understood. From a clinical point of view, these patients present with clinical and laboratory features that recall other life-threatening conditions associated with acute viral infections such as HLH. Unfortunately, we have few information regarding the longitudinal course of this specific subset of patients, and it is difficult to state that they present the same course that patients with HLH unrelated to SARS-CoV-2 infection. According to the criteria that are used for the diagnosis of HLH in daily practice, the frequency of patients with severe COVID-19 that have been confirmed as having HLH is very low, something to be expected considering that HLH is per se a very rare condition. However, the current pandemic context can distort this if we consider the huge number of people hospitalised worldwide by severe COVID-19. The total number of COVID-19 patients fulfilling the HLH criteria

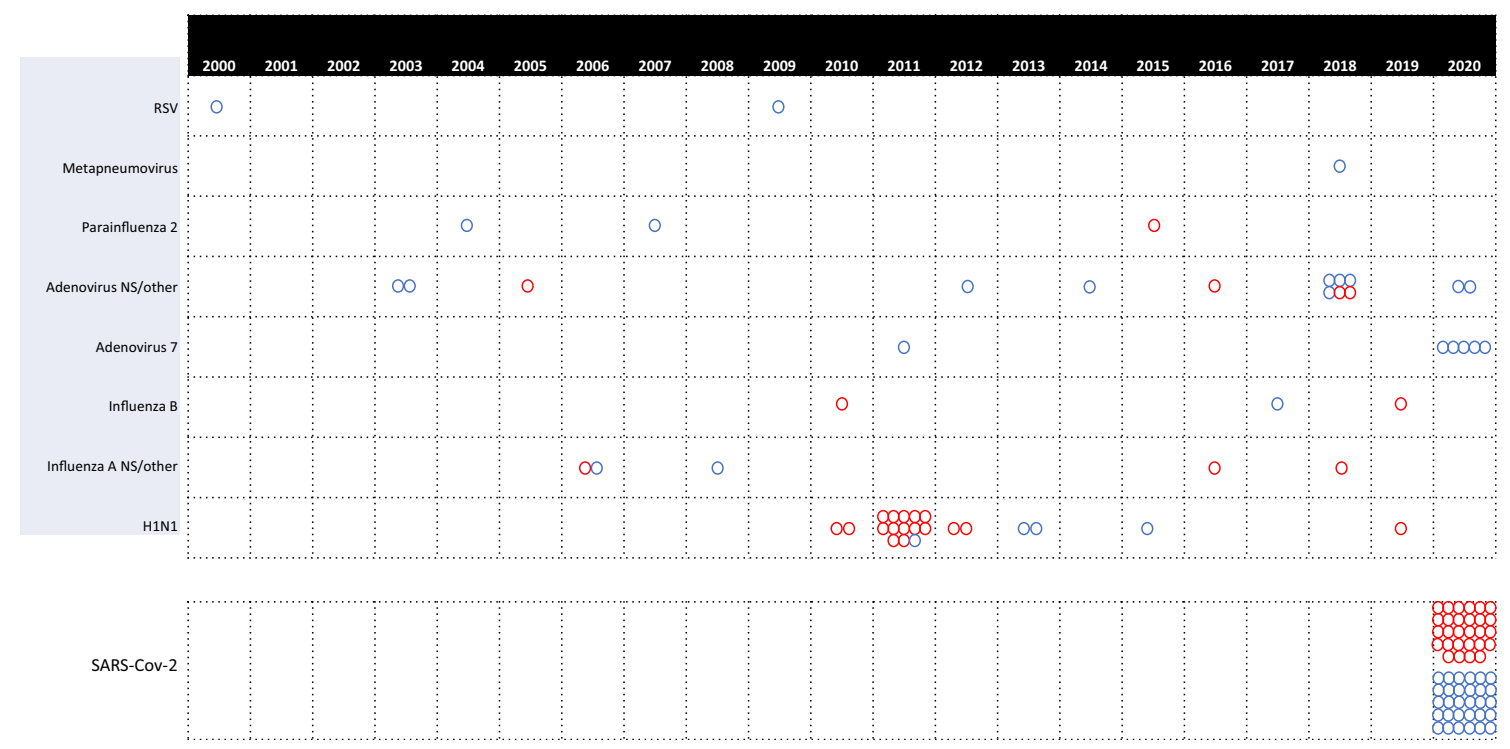

Fig. 1 Viral pneumonias (adenovirus, RSV, metapneumovirus, influenza, and parainfluenza viruses) associated with HLH: reported cases (see references in Supplementary Table 1). Included the 28 reported cases of HLH related to COVID-19 fulfilling at least 5 HLH-2004 criteria and/or having a HScore $>169$, and the 30 children fulfilling MAS criteria. Red circles $=$ adults, blue circles $=$ children 
is, at the time of writing this review, almost 10 times higher than all the cases of HLH reported in 2020 related to other respiratory viruses reported (Fig. 1). From a practical point of view, we recommend to assess the possible development of HLH in patients with severe COVID-19 who present with a highly suspicious clinical and laboratory profile, with the aim of evaluating for them the use of specific therapeutic approaches that could target immunopathological pathways common for both severe COVID-19 and HLH.

Supplementary Information The online version contains supplementary material available at https://doi.org/10.1007/s10067-020-05569-4.

Contributors SR and PB-Z performed the literature review; SR, PB-Z and MR-C drafted the manuscript. All authors reviewed and edited the manuscript and accepted its final form.

\section{Compliance with ethical standards}

Competing interests MR-C reported consultancy for BMS, Gilead; SR not declare, PBZ not declare, ASA not declare, AFC not declare, MJSC not declare.

\section{References}

1. Connors JM, Levy JH (2020) COVID-19 and its implications for thrombosis and anticoagulation. Blood 135:2033-2040

2. Monti S, Montecucco C (2020) Diagnostic and therapeutic challenges for patients with ANCA-associated vasculitides at the time of COVID-19. Response to: 'Rituximab for granulomatosis with polyangiitis in the pandemic of COVID-19: lessons from a case with severe pneumonia' by Guilpain et al. Ann Rheum Dis 80: e11. https://doi.org/10.1136/annrheumdis-2020-217555

3. England JT, Abdulla A, Biggs CM et al (2020) Weathering the COVID-19 storm: lessons from hematologic cytokine syndromes. Blood Rev 100707. https://doi.org/10.1016/j.blre.2020.100707

4. Carvelli J, Piperoglou C, Farnarier C, on behalf of the HLH-2007 Study Group (2020) Functional and genetic testing in adults with HLH reveals an inflammatory profile rather than a cytotoxicity defect. Blood 136:542-552

5. Moore JB, June CH (2020) Cytokine release syndrome in severe COVID-19. Science 368:473-474

6. Cheng L, Li H, Li L et al (2020) Ferritin in the coronavirus disease 2019 (COVID-19): a systematic review and meta-analysis. J Clin Lab Anal 34:e23618

7. Opoka-Winiarska V, Grywalska E, Roliński J (2020) Could hemophagocytic lymphohistiocytosis be the core issue of severe COVID-19 cases? BMC Med 18:214

8. Gustine JN, Jones D (2020) Immunopathology of hyperinflammation in COVID-19. Am J Pathol 191:4-17

9. Kuri-Cervantes L, Pampena MB, Meng W et al (2020) Comprehensive mapping of immune perturbations associated with severe COVID-19. Sci Immunol 5:eabd7114

10. RCPCH Guidance: Paediatric multisystem inflammatory syndrome temporally associated with COVID-19. Royal College of Paediatrics and Child Health https://www.rcpch.ac.uk/sites/ default/files/2020-05/COVID-19-Paediatric-multisystem-\% 20inflammatory\%20syndrome-20200501.pdf. Accessed October 15,2020
11. Centers for Disease Control and Prevention. Emergency preparedness and response: health alert network. Published May 14, 2020. Accessed October 15, 2020. https://emergency.cdc.gov/han/ 2020/han00432.asp

12. World Health Organization. Multisystem inflammatory syndrome in children and adolescents with COVID-19. Published May 15, 2020. Accessed October 15, 2020. https://www.who.int/ publications-detail/multisystem-inflammatory-syndrome-inchildren-and-adolescents-with-covid-19

13. Nijman RG, De Guchtenaere A, Koletzko B et al (2020) Pediatric inflammatory multisystem syndrome: statement by the pediatric section of the European Society for Emergency Medicine and European Academy of pediatrics. Front Pediatr 8:490

14. McCrindle BW, Rowley AH, Newburger JW, American Heart Association Rheumatic Fever, Endocarditis, and Kawasaki Disease Committee of the Council on Cardiovascular Disease in the Young; Council on Cardiovascular and Stroke Nursing; Council on Cardiovascular Surgery and Anesthesia; and Council on Epidemiology and Prevention et al (2017) Diagnosis, treatment, and long-term management of Kawasaki disease: a scientific statement for health professionals from the American Heart Association. Circulation 135:e927-e999

15. Harwood R, Allin B, Jones CE, PIMS-TS National Consensus Management Study Group et al (2020) A national consensus management pathway for paediatric inflammatory multisystem syndrome temporally associated with COVID-19 (PIMS-TS): results of a national Delphi process. Lancet Child Adolesc Health S23524642:30304-30307

16. Morris SB, Schwartz NG, Patel P, Abbo L, Beauchamps L, Balan S, Lee EH, Paneth-Pollak R, Geevarughese A, Lash MK, Dorsinville MS, Ballen V, Eiras DP, Newton-Cheh C, Smith E, Robinson S, Stogsdill P, Lim S, Fox SE, Richardson G, Hand J, Oliver NT, Kofman A, Bryant B, Ende Z, Datta D, Belay E, Godfred-Cato S (2020) Case series of multisystem inflammatory syndrome in adults associated with SARS-CoV-2 infection United Kingdom and United States, March-August 2020. MMWR Morb Mortal Wkly Rep 69:1450-1456

17. Carvelli J, Demaria O, Vély F, Batista L, Cordier PY, Le Dault E, Guervilly C, Explore COVID-19 IPH group; Explore COVID-19 Marseille Immunopole group et al (2020) Association of COVID19 inflammation with activation of the C5a-C5aR1 axis. Nature 588:146-150

18. Chau AS, Weber AG, Maria NI, Narain S, Liu A, Hajizadeh N, Malhotra P, Bloom O, Marder G, Kaplan B (2020) The longitudinal immune response to coronavirus disease 2019: chasing the cytokine storm. Arthritis Rheumatol. https://doi.org/10.1002/art.41526

19. Colafrancesco S, Alessandri C, Conti F, Priori R (2020) COVID-19 gone bad: a new character in the spectrum of the hyperferritinemic syndrome? Autoimmun Rev 19:102573

20. Brudno JN, Kochenderfer JN (2016) Toxicities of chimeric antigen receptor T cells: recognition and management. Blood 127:33213330

21. Sinha P, Calfee CS, Cherian S et al (2020) Prevalence of phenotypes of acute respiratory distress syndrome in critically ill patients with COVID-19: a prospective observational study. Lancet Respir Med S2213-2600:30366

22. Sinha P, Matthay MA, Calfee CS (2020) Is a 'Cytokine Storm' Relevant to COVID-19? JAMA Intern Med. https://doi.org/10. 1001/jamainternmed.2020.3313

23. Leisman DE, Ronner L, Pinotti R et al (2020) Cytokine elevation in severe and critical COVID-19: a rapid systematic review, metaanalysis, and comparison with other inflammatory syndromes. Lancet Respir Med S2213-2600:30404-30405

24. Merad M, Martin JC (2020) Pathological inflammation in patients with COVID-19: a key role for monocytes and macrophages. Nat Rev Immunol 20:355-362 
25. Sinha P, Calfee CS (2019) Phenotypes in acute respiratory distress syndrome: moving towards precision medicine. Curr Opin Crit Care 25:12-20

26. Channappanavar R, Perlman S (2017) Pathogenic human coronavirus infections: causes and consequences of cytokine storm and immunopathology. Semin Immunopathol 39:529-539

27. Ronit A, Berg RMG, Bay JT et al (2020) Compartmental immunophenotyping in COVID-19 ARDS: a case series. J Allergy Clin Immunol S0091-6749:31317-31318

28. Ramos-Casals M, Brito-Zerón P, Armando López-Guillermo A et al (2014) Adult haemophagocytic syndrome. Lancet 383:15031516

29. Merad M, Martin JC (2020) Pathological inflammation in patients with COVID-19: a key role for monocytes and macrophages. Nat Rev Immunol 20:355-362

30. Perlman S, Dandekar AA (2005) Immunopathogenesis of coronavirus infections: implications for SARS. Nat Rev Immunol 5:917927

31. Gómez-Rial J, Rivero-Calle I, Salas A et al (2020) Role of monocytes/macrophages in Covid-19 pathogenesis: implications for therapy. Infect Drug Resist 13:2485-2493

32. Opoka-Winiarska V, Grywalska E, Roliński J (2020) Could hemophagocytic lymphohistiocytosis be the core issue of severe COVID-19 cases? BMC Med 18:214

33. Wood H, Jones JR, Hui K, Mare T, Pirani T, Galloway J, Metaxa V, Benjamin R, Rutherford A, Cain S, Kulasekararaj AG (2020) Secondary HLH is uncommon in severe COVID-19. Br J Haematol 190:e283-e285

34. Hakim NN, Chi J, Olazagasti C et al (2020) Secondary hemophagocytic lymphohistiocytosis versus cytokine release syndrome in severe COVID-19 patients. Exp Biol Med (Maywood). https://doi.org/10.1177/1535370220962043

35. Loscocco GG, Malandrino D, Barchiesi S, Berni A, Poggesi L, Guglielmelli P, Vannucchi AM (2020) The HScore for secondary hemophagocytic lymphohistiocytosis, calculated without a marrow biopsy, is consistently low in patients with COVID-19. Int J Lab Hematol 42:e270-e273. https://doi.org/10.1111/ijlh.13310

36. Prieto-Pérez L, Fortes J, Soto C, Vidal-González Á, Alonso-Riaño M, Lafarga M, Cortti MJ, Lazaro-Garcia A, Pérez-Tanoira R, Trascasa Á, Antonio A, Córdoba R, Rodríguez-Pinilla SM, Cedeño O, Peces-Barba G, Fernández-Ormaechea I, Díez Medrano MJ, López de Las Heras M, Cabello A, Petkova E, Álvarez B, Carrillo I, Silva AM, Castellanos M, Calpena S, Valverde-Monge M, Fresneda D, Rubio-Martín R, Cornejo I, Astilleros Blanco de Cordova L, de la Fuente S, Recuero S, Górgolas M, Piris MA (2020) Histiocytic hyperplasia with hemophagocytosis and acute alveolar damage in COVID-19 infection. Mod Pathol 33:2139-2146

37. Ruscitti P, Bruno F, Berardicurti O, Acanfora C, Pavlych V, Palumbo P, Conforti A, Carubbi F, di Cola I, di Benedetto P, Cipriani P, Grassi D, Masciocchi C, Iagnocco A, Barile A, Giacomelli R (2020) Lung involvement in macrophage activation syndrome and severe COVID-19: results from a cross-sectional study to assess clinical, laboratory and artificial intelligenceradiological differences. Ann Rheum Dis 79:1152-1155

38. Feld J, Tremblay D, Thibaud S, Kessler A, Naymagon L (2020) Ferritin levels in patients with COVID-19: a poor predictor of mortality and hemophagocytic lymphohistiocytosis. Int J Lab Hematol 42:773-779. https://doi.org/10.1111/ijlh.13309

39. Lee PY, Day-Lewis M, Henderson LA, Friedman KG, Lo J, Roberts JE, Lo MS, Platt CD, Chou J, Hoyt KJ, Baker AL, Banzon TM, Chang MH, Cohen E, de Ferranti SD, Dionne A, Habiballah S, Halyabar O, Hausmann JS, Hazen MM, Janssen E, Meidan E, Nelson RW, Nguyen AA, Sundel RP, Dedeoglu F, Nigrovic PA, Newburger JW, Son MBF (2020) Distinct clinical and immunological features of SARS-CoV-2-induced multisystem inflammatory syndrome in children. J Clin Invest 130:5942-5950

40. Kerget B, Kerget F, Koçak AO, Kızıltunç A, Araz Ö, Uçar EY, Akgün M (2020) Are serum interleukin 6 and surfactant protein D levels associated with the clinical course of COVID-19? Lung 198: 777-784

41. Clark KEN, Nevin WD, Mahungu T, Lachmann H, Singh A (2020) Assessment of the haemophagocytic lymphohistiocytosis HScore in patients with COVID-19. Clin Infect Dis. https://doi.org/10. 1093/cid/ciaa1463

42. Giamarellos-Bourboulis EJ, Netea MG, Rovina N et al (2020) Complex immune dysregulation in COVID-19 patients with severe respiratory failure. Cell Host Microbe 27(6):992-1000.e3. https:// doi.org/10.1016/j.chom.2020.04.009

43. Agbuduwe C, Basu S (2020) Haematological manifestations of COVID-19: from cytopenia to coagulopathy. Eur J Haematol 105:540-546. https://doi.org/10.1111/ejh.13491

44. Ren H, Yang Y, Wang F, Yan Y, Shi X, Dong K, Yu X, Zhang S (2020) Association of the insulin resistance marker TyG index with the severity and mortality of COVID-19. Cardiovasc Diabetol 19: 58

45. Nakamura H, Miyagi K, Otsuki M, Higure Y, Nishiyama N, Kinjo T, Nakamatsu M, Haranaga S, Tateyama M, Fujita J (2020) Acute hypertriglyceridaemia caused by Ttocilizumab in a patient with severe COVID-19. Intern Med 59:2945-2949. https://doi.org/10. 2169/internalmedicine.5244-20

46. Morrison AR, Johnson JM, Ramesh M, Bradley P, Jennings J, Smith ZR (2020) Acute hypertriglyceridemia in patients with COVID-19 receiving tocilizumab. J Med Virol 92:1791-1792. https://doi.org/10.1002/jmv.25907

47. Connors JM, Levy JH (2020) COVID-19 and its implications for thrombosis and anticoagulation. Blood 135:2033-2040

48. Tang N, Li D, Wang X, Sun Z (2020) Abnormal coagulation parameters are associated with poor prognosis in patients with novel coronavirus pneumonia. J Thromb Haemost 18:844-847

49. Pineton de Chambrun M, Frere C, Miyara M, Amoura Z, MartinToutain I, Mathian A, Hekimian G, Combes A (2020) High frequency of antiphospholipid antibodies in critically ill COVID-19 patients: a link with hypercoagulability? J Intern Med. https://doi. org/10.1111/joim. 13126

50. Casas-Rojo JM, Antón-Santos JM, Millán-Núñez-Cortés J, Lumbreras-Bermejo C, Ramos-Rincón JM, Roy-Vallejo E, Artero-Mora A, Arnalich-Fernández F, García-Bruñén JM, Vargas-Núñez JA, Freire-Castro SJ, Manzano-Espinosa L, Perales-Fraile I, Crestelo-Viéitez A, Puchades-Gimeno F, RodillaSala E, Solís-Marquínez MN, Bonet-Tur D, Fidalgo-Moreno MP, Fonseca-Aizpuru EM, Carrasco-Sánchez FJ, Rabadán-Pejenaute E, Rubio-Rivas M, Torres-Peña JD, Gómez-Huelgas R, en nombre del Grupo SEMI-COVID-19 Network, en nombre del Grupo SEMI-COVID-19 Network (2020) Clinical characteristics of patients hospitalized with COVID-19 in Spain: results from the SEMI-COVID-19 Registry. Rev Clin Esp 220:480-494

51. Wu C, Chen X, Cai Y, Xia J', Zhou X, Xu S, Huang H, Zhang L, Zhou X, du C, Zhang Y, Song J, Wang S, Chao Y, Yang Z, Xu J, Zhou X, Chen D, Xiong W, Xu L, Zhou F, Jiang J, Bai C, Zheng J, Song Y (2020) Risk factors associated with acute respiratory distress syndrome and death in patients with coronavirus disease 2019 pneumonia in Wuhan, China. JAMA Intern Med 180:934-943

52. Ruscitti P, Berardicurti O, Barile A, Cipriani P, Shoenfeld Y, Iagnocco A, Giacomelli R (2020) Severe COVID-19 and related hyperferritinaemia: more than an innocent bystander? Ann Rheum Dis 79:1515-1516

53. Wang X, Huang K, Jiang H, Hua L, Yu W, Ding D, Wang K, Li X, Zou Z, Jin M, Xu S (2020) Long-term existence of SARS-CoV-2 in COVID-19 patients: host immunity, viral virulence, and transmissibility. Virol Sin. https://doi.org/10.1007/s12250-020-00308-0 
54. Jeannet R, Daix T, Formento R, Feuillard J, François B (2020) Severe COVID-19 is associated with deep and sustained multifaceted cellular immunosuppression. Intensive Care Med 46:17691771

55. Mazzoni A, Salvati L, Maggi L, Capone M, Vanni A, Spinicci M, Mencarini J, Caporale R, Peruzzi B, Antonelli A, Trotta M, Zammarchi L, Ciani L, Gori L, Lazzeri C, Matucci A, Vultaggio A, Rossi O, Almerigogna F, Parronchi P, Fontanari P, Lavorini F, Peris A, Rossolini GM, Bartoloni A, Romagnani S, Liotta F, Annunziato F, Cosmi L (2020) Impaired immune cell cytotoxicity in severe COVID-19 is IL-6 dependent. J Clin Invest 130:4694 4703

56. van Eeden C, Khan L, Osman MS, Cohen Tervaert JW (2020) Natural killer cell dysfunction and its role in COVID-19. Int J Mol Sci 21:6351

57. Buono A, Lidbury JA, Wood C, Wilson-Robles H, Dangott LJ, Allenspach K, Suchodolski JS, Steiner JM (2019) Development, analytical validation, and initial clinical evaluation of a radioimmunoassay for the measurement of soluble CD25 concentrations in canine serum. Vet Immunol Immunopathol 215:109904

58. Hou H, Zhang B, Huang H, Luo Y, Wu S, Tang G, Liu W, Mao L, Mao L, Wang F, Sun Z (2020) Using IL-2R/lymphocytes for predicting the clinical progression of patients with COVID-19. Clin Exp Immunol 201:76-84

59. Yan Y, Yang Y, Wang F, Ren H, Zhang S, Shi X, Yu X, Dong K (2020) Clinical characteristics and outcomes of patients with severe covid-19 with diabetes. MJ Open Diabetes Res Care 8:e001343

60. Meng Y, Lu W, Guo E, Liu J, Yang B, Wu P, Lin S, Peng T, Fu Y, Li F, Wang Z, Li Y, Xiao R, Liu C, Huang Y, Lu F, Wu X, You L, Ma D, Sun C, Wu P, Chen G (2020) Cancer history is an independent risk factor for mortality in hospitalized COVID-19 patients: a propensity score-matched analysis. J Hematol Oncol 13:75

61. Faguer S, Del Bello A, Abravanel F et al (2020) Tocilizumab for hemophagocytic syndrome in a kidney transplant recipient with COVID-19. Ann Intern Med 173:501-503

62. Dewaele K, Claeys R (2020) Hemophagocytic lymphohistiocytosis in SARS-CoV-2 infection. Blood 135:2323

63. Nicholls JM, Poon LL, Lee KC et al (2003) Lung pathology of fatal severe acute respiratory syndrome. Lancet 361:1773-1778

64. Abdollahi A, Beigmohammadi MT, Safaei M, Mehrtash V, Jafarzadeh B (2020) A histopathological observation regarding the possibility of hemophagocytic lymphohistiocytosis in COVID-19 patients. J Gastrointestin Liver Dis 29:475-476

65. Adrogué AH, Mithani F, Ibrahim HN, Schwartz MR, Gaber L, Hebert SA, Adrogué HE (2020) A kidney transplant recipient with coronavirus disease 2019: utility of a prognostication score. Transplant Proc 52:2688-2692

66. Amaral LTW, Fonseca EKUN, Jacomelli M et al (2020) Hemophagocytic syndrome: a potential COVID-19 complication. J Bras Pneumol 46:e20200296

67. Amir R, Kichloo A, Singh J et al (2020) Epstein-Barr virus versus novel coronavirus-induced hemophagocytic lymphohistocytosis: the uncharted waters. J Investig Med High Impact Case Rep 8: 2324709620950107

68. Clark KEN, Oliver Collas O, Lachmann H et al (2020) Safety of intravenous anakinra in COVID-19 with evidence of hyperinflammation, a case series. Rheumatol Adv Pract 4:rkaa040

69. Dancy LH, Abu-Own H, Byrne J, Pareek N (2020). Extensive coronary artery thrombosis complicating COVID-19 infection and haemophagocytic lymphohistiocytosis. EuroIntervention; EIJ-D20-00636. https://doi.org/10.4244/EIJ-D-20-00636

70. Dharsandiya M, Shah K, Patel K, Patel T, Patel A, Patel A (2020) SARS-CoV-2 viral sepsis with meningoencephalitis. Indian J Med Microbiol 38:219-221

71. Dewaele K, Claeys R (2020) Hemophagocytic lymphohistiocytosis in SARS-CoV-2 infection. Blood 135:2323
72. Dimopoulos G, de Mast Q, Markou N et al (2020) Favorable anakinra responses in severe Covid-19 patients with secondary hemophagocytic lymphohistiocytosis. Cell host microbe 28:117123.e1

73. Fernandez J, Gratacos-Ginès J, Olivas $\mathrm{P}$, Costa $\mathrm{M}$, Nieto $\mathrm{S}$, Mateo D, Sánchez MB, Aguilar F, Bassegoda O, Ruiz P, Caballol B, Pocurull A, Llach J, Mustieles MJ, Cid J, Reverter E, Toapanta ND, Hernández-Tejero M, Martínez JA, Claria J, Fernández C, Mensa J, Arroyo V, Castro P, Lozano M, for the Covid Clinic Critical Care (CCCC) Group, Covid Clinic Critical Care (CCCC) Group (2020) Plasma exchange: an effective rescue therapy in critically ill patients with coronavirus disease 2019 infection. Crit Care Med 48:e1350-e1355. https://doi.org/10.1097/CCM. 0000000000004613

74. Franzetti M, Pozzetti U, Carugati M, Pandolfo A, Molteni C, Faccioli P, Castaldo G, Longoni E, Ormas V, Iemoli E, Piconi S (2020) Interleukin-1 receptor antagonist anakinra in association with remdesivir in severe COVID-19: a case report. Int J Infect Dis 97:215-218

75. Haigh K, Syrimi ZJ, Irvine S et al (2020) Hyperinflammation with COVID-19: the key to patient deterioration? Clin Infect Pract 2020: 100033

76. Klocperk A, Parackova Z, Dissou J, Malcova H, Pavlicek P, Vymazal T, Dolezalova P, Sediva A (2020) Case report: systemic inflammatory response and fast recovery in a pediatric patient with COVID-19. Front Immunol 11:1665

77. Licciardi F, Pruccoli G, Denina M, Parodi E, Taglietto M, Rosati S, Montin D (2020) SARS-CoV-2-induced Kawasaki-like hyperinflammatory syndrome: a novel COVID phenotype in children. Pediatrics 146:e20201711

78. Lima R, Cortinhas Filho C, Ferreira Filho CM et al (2020) Hemophagocytic syndrome and COVID-19. Respir Med Case Rep 31:101162

79. Lolachi S, Morin S, Coen M, Samii K, Calmy A, Serratrice J (2020) Macrophage activation syndrome as an unusual presentation of paucisymptomatic severe acute respiratory syndrome coronavirus 2 infection: a case report. Medicine (Baltimore) 99:e21570

80. Prilutskiy A, Kritselis M, Shevtsov A, Yambayev I, Vadlamudi C, Zhao Q, Kataria Y, Sarosiek SR, Lerner A, Sloan JM, Quillen K, Burks EJ (2020) SARS-CoV-2 infection-associated hemophagocytic lymphohistiocytosis. Am J Clin Pathol 154:466474

81. Quintana-Ortega C, Remesal A, Ruiz de Valbuena M et al (2020) Fatal outcome of anti-MDA5 juvenile dermatomyositis in a paediatric COVID-19 patient: a case report. Mod Rheumatol Case Rep 5: 101-107

82. Radbel J, Narayanan N, Bhatt PJ (2020) Use of Tocilizumab for COVID-19-induced cytokine release syndrome: a cautionary case report. Chest 158:e15-e19

83. Sorà $\mathrm{F}$, Chiusolo $\mathrm{P}$, Laurenti L et al (2020) SARS CoV 2 infection in chronic myelogenous leukemia: severe hematological presentation. Transfus Apher Sci 59:102881

84. Mehta P, McAuley DF, Brown M et al (2020) COVID-19: consider cytokine storm syndromes and immunosuppression. Lancet (London, England) 395:1033-1034

85. Loscocco GG (2020) Secondary hemophagocytic lymphohistiocytosis, HScore and COVID-19. Int J Hematol 112: $125-126$

86. Webb BJ, Peltan ID, Jensen P, Hoda D, Hunter B, Silver A, Starr N, Buckel W, Grisel N, Hummel E, Snow G, Morris D, Stenehjem E, Srivastava R, Brown SM (2020) Clinical criteria for COVID-19associated hyperinflammatory syndrome: a cohort study. Lancet Rheumatol 2:e754-e763. https://doi.org/10.1016/S2665-9913(20) 30343-X 
87. Alunno A, Carubbi F, Rodríguez-Carrio J (2020) Storm, typhoon, cyclone or hurricane in patients with COVID-19? Beware of the same storm that has a different origin. RMD Open 6:e01295

88. Verdoni L, Mazza A, Gervasoni A, Martelli L, Ruggeri M, Ciuffreda M, Bonanomi E, D'Antiga L (2020) An outbreak of severe Kawasaki-like disease at the Italian epicentre of the SARSCoV-2 epidemic: an observational cohort study. Lancet 395:17711778

89. Belot A, Antona D, Renolleau S et al (2020) SARS-CoV-2-related paediatric inflammatory multisystem syndrome, an epidemiological study, France, 1 March to 17 May 2020. Euro Surveill 25:2001010

90. Henderson LA, Canna SW, Schulert GS, Volpi S, Lee PY, Kernan KF, Caricchio R, Mahmud S, Hazen MM, Halyabar O, Hoyt KJ, Han J, Grom AA, Gattorno M, Ravelli A, Benedetti F, Behrens EM, Cron RQ, Nigrovic PA (2020) On the alert for cytokine storm: immunopathology in COVID-19. Arthritis Rheumatol 72:1059 1063

91. RECOVERY Collaborative Group, Horby P, Lim WS, Emberson JR et al (2020) Dexamethasone in hospitalized patients with Covid19 - preliminary report. N Engl J Med NEJMoa2021436. https:// doi.org/10.1056/NEJMoa2021436

92. Hamizi K, Aouidane S, Belaaloui G (2020) Etoposide-based therapy for severe forms of COVID-19. Med Hypotheses 142:109826

93. Huang E, Jordan SC (2020) Tocilizumab for Covid-19 - the ongoing search for effective therapies. N Engl J Med 383:2387-2388
94. Hoang TN, Pino M, Boddapati AK et al (2020) Baricitinib treatment resolves lower-airway macrophage inflammation and neutrophil recruitment in SARS-CoV-2-infected rhesus macaques. Cell S0092-8674:31466-31465

95. Kalil AC, Patterson TF, Mehta AK et al (2020) Baricitinib plus remdesivir for hospitalized adults with Covid-19. N Engl J Med; NEJMoa2031994. https://doi.org/10.1056/NEJMoa2031994

96. De Luca G, Cavalli G, Campochiaro C et al (2020) GM-CSF blockade with mavrilimumab in severe COVID-19 pneumonia and systemic hyperinflammation: a single-centre, prospective cohort study. Lancet Rheumatol 2:e465-e473

97. Melody M, Nelson J, Hastings J, Propst J, Smerina M, Mendez J, Guru P (2020) Case report: use of lenzilumab and tocilizumab for the treatment of coronavirus disease 2019. Immunotherapy 12: $1121-1126$

98. Locatelli F, Jordan MB, Allen C, Cesaro S, Rizzari C, Rao A, Degar B, Garrington TP, Sevilla J, Putti MC, Fagioli F, Ahlmann M, Dapena Diaz JL, Henry M, de Benedetti F, Grom A, Lapeyre G, Jacqmin P, Ballabio M, de Min C (2020) Emapalumab in children with primary hemophagocytic lymphohistiocytosis. N Engl J Med 382:1811-1822

Publisher's note Springer Nature remains neutral with regard to jurisdictional claims in published maps and institutional affiliations. 